\title{
Sobre antropologías en plural y disidentes. Entrevista con Eduardo Restrepo
}

\author{
GONZALO DÍAZ CROVETTO \\ Universidad Católica de Temuco, Chile
}

RECEPCIÓN: 30/IO/2OI3 • ACEPTACIÓN: 4/I I/20I3

Las VIII Jornadas de Antropología del Departamento de Antropología de la Universidad Católica de Temuco, realizadas entre los días 7 y 9 de octubre del 20I3, contaron con la participación activa del profesor Eduardo Restrepo. ${ }^{1}$ Esta entrevista fue realizada una vez finalizada las jornadas, por lo que recogió diferentes puntos, reflexiones y cuestionamientos que surgieron durante el evento académico. Cabe señalar que el profesor Restrepo, quien es parte del Departamento de Estudios Culturales de la Facultad de Ciencias Sociales de la Universidad Javeriana de Colombia, tiene una vasta trayectoria en el campo de las ciencias sociales, la antropología y los estudios culturales; ha publicado un sinfín de artículos en autoría y coautoría en diversas revistas especializadas, y ha escrito también varios libros, siendo el más reciente Antropologías y estudios culturales publicado por Siglo XXI durante el año 20I 2. Restrepo también es miembro fundador de la Red de Antropologías Mundiales. ${ }^{2}$

DíAz CrovetTo: Quisiera iniciar la conversación con algunas preguntas rela-

I. El profesor Eduardo Restrepo participó como expositor de una mesa redonda titulada «Problemáticas en antropología contemporánea: enfoques, diálogos y reflexiones posibles», además fue comentador de una mesa titulada «Encuentros de la antropología del sur» y nos brindó una conferencia titulada "Antropologías disidentes: urgencias ante la muerte de lo político».

2. Parte de su extenso del currículo se encuentra disponible en <http://www.ramwan.net/restrepo/publicaciones.htm>. 
cionadas con nuestra reciente experiencia en las Jornadas de Antropología en la Universidad Católica de Temuco, sobre cuestiones que discutimos los días del evento. En primer lugar te pediría que conversemos sobre antropologías en plural, más allá de propuestas específicas como la de la antropología del sur de Krotz $^{3}$ o de otras propuestas similares. Para ti, ¿cuál sería, entonces, la diferencia entre lo que aprendimos y cómo nos fue enseñada la antropología, y lo que hoy enseñamos, practicamos y entendemos por antropología?

RESTREPo: Bueno, sobre antropologías en plural, a mí me ha llamado mucho la atención que cuando estudiamos antropología o cuando enseñamos antropología, intentamos establecer una definición de lo que es antropología y, al establecer esa definición, ubicamos o identificamos una serie de características que estarían estableciendo qué es la antropología en singular y de una manera transhistórica. Al asumir que la antropología es con tales y tales características se impone una definición esencialista de la antropología. Lo que más me ha llamado la atención es que cuando uno conoce lo que efectivamente, históricamente, se ha hecho en diferentes comunidades antropológicas, antes y ahora, uno encuentra que lo que prima es la diferencia en cosas muy concretas; por ejemplo: el objeto.

Hay alguna gente que define la antropología por la cultura. Para algunos la antropología sería el estudio de la cultura, pero uno va a otros lugares a escudriñar la historia y se da cuenta que hay muchas antropologías, como la antropología social británica o la etnología francesa, que no tienen o no son definidas necesariamente por la cultura, sino que tienen otros objetos de estudio. En Colombia te encuentras con colegas que convencidos definen a la antropología como el estudio del hombre (así, el hombre sin comillas) y a renglón seguido se dice que se compone por «cuatro ramas... la arqueología, la antropología física, la lingüística y la antropología social o cultural». No obstante, si miras sus propias prácticas o si vas a otros países (como Francia, Sudáfrica, China o tantos otros), esas narrativas que aparentemente definen claramente a la antropología se ven cuestionadas.

La pluralización de las antropologías surge de contrastar lo que se puede llamar antropologías de manual (las definiciones de manual de antropología que reproducen a menudo con ingenuidad muchos colegas) con las prácticas históricamente articuladas como antropología. Ahí uno encuentra que no hay

3. Véase, por ejemplo, Krotz (2005). 
un objeto sino muchos, uno encuentra que no hay un método sino que hay muchos. En un lugar concreto como México o como Brasil o como Buenos Aires, uno encuentra que lo que ha habitado la antropología son una serie de tensiones y de diferencias, y a veces de inconmensurabilidades, que hay que tener en consideración, que no se pueden borrar en nombre de definiciones de manual, de concepciones esencializadas de una identidad disciplinaria garantizada por un objeto, método, panteón de héroes culturales... Entonces eso de la pluralización de la antropología es fundamentalmente acercarnos a una perspectiva no esencialista, sin buscar una esencia o una identidad de la antropología más allá de lo que es la antropología como una práctica social y culturalmente situada, una práctica que está ligada a una serie de instituciones, a unas subjetividades, a unas narrativas y también a unas disputas al interior lo que esto define.

Lo otro que hay que tener presente con esto de la pluralización, es que la pluralización apunta a cuestionar ciertas creencias o ciertos cerramientos ideológicos de algunos antropólogos y de algunas posiciones y tradiciones antropológicas; por ejemplo, hay algunos antropólogos muy respetuosos, muy valiosos que dicen que la antropología está definida por el estudio de la diferencia, por la diferencia radical, la alteridad, por los otros de Occidente... Desde estas posiciones algunos colegas afirman que De las Casas es una especie de proto-antropología porque él estaba reflexionando sobre los indígenas. Igualmente, desde estos colegas, las reflexiones y estudios de algunas figuras de las élites criollas antes, durante y después de los procesos de independencia con respecto a las sociedades indígenas, eso haría parte de la antropología más propia, más de acá. Entonces ahí, en esas narrativas, hay una equivalencia entre antropología y estudios de poblaciones indígenas por ejemplo, o de una manera más general entre antropología y alteridad. Pero, en la práctica, mucha antropología se ha hecho con preguntas y en relación con poblaciones que no son poblaciones indígenas. Por ejemplo, el trabajo sobre antropología del desarrollo o el asunto de la antropología de la modernidad o el asunto de la antropología del Estado. Si la antropología estuviese circunscrita al estudio de la alteridad radical encarnada en la indianidad, entonces cómo pensar el trabajo de la antropología del Estado o la etnografía de Internet, o la antropología de la cibercultura. Si la antropología estuviera definida por esa equivalencia con la alteridad radical, en estos casos no encontramos esa alteridad radical, pero, sin embargo, reconocemos esas prácticas como antropológicas. Ahora pienso que mirar hacia atrás para subsumir lo que hace De las Casas, 
o ciertas figuras de la élite criolla como antropología, es un gesto de imperialismo disciplinario.

Entonces hacía dónde lleva la pluralización.A tomarse en serio el hecho de que nosotros también tenemos un conjunto de representaciones sobre lo que aparece como antropología, que a veces epistemologizamos e ideologizamos de forma tal que las naturalizamos, haciendo que algunas autoridades muy serias - te puedo dar muchos nombres- asuman eso como verdades obvias. Entonces la pluralización de la antropología también es una invitación a desideologizar, a desnaturalizar lo que son ciertas «grandes verdades» que constituyen lo que a mí me gusta mencionar como el sentido común disciplinario, es decir, el lugar naturalizado que en general no cuestionamos y menos cuando lo dicen nuestros profesores con grandes capitales simbólicos y autoridad.

Díaz Crovetto: En ese sentido, comparado, por ejemplo, con el enfoque de Roberto Cardoso de Oliveira sobre la matriz disciplinar ${ }^{4}$ y dentro de la imposición sobre lo que es el mínimo común, o la sustancia sobre lo que es lo antropológico, ¿dónde tú podrías ver límites o matrices de la antropología, o bien, hasta dónde llega la antropología?

Restrepo: Pienso que la pregunta no hay que resolverla epistemológicamente, sino etnográfica e históricamente. Entonces en este punto en particular estoy en profundo desacuerdo con la idea de Cardoso de diferenciar una matriz disciplinaria asociada a los paradigmas francés y anglosajón, de los estilos antropológicos que se asociarían a aquellas otras antropologías que él denomina periféricas. Esto es reproducir una distinción asimétrica entre ciertas maneras de hacer antropología como paradigmáticas, mientras que otras se conciben como diletantes copias que no llegan al estatus de constituirse como paradigmas. Considero que la distinción de Cardoso de Oliveira puede llevar al error de pensar que existen algo así como unas antropologías de verdad-verdad que contribuyen a la matriz disciplinaria que definiría una identidad de la antropología y unas antropologías diletantes que más o menos se apropian de esos paradigmas. Me gusta su idea de estilos antropológicos para indicar la heterogeneidad de las antropologías, para señalar cómo están histórica, cultural y políticamente situadas. Pero el paso que le falta a Cardoso de Oliveira es desacralizar las antropologías metropolitanas para conceptuarlas también como

4. Véase, por ejemplo, Cardoso de Oliveira (1988). 
estilos antropológicos específicos. Así tomaría distancia del eurocentrismo que le lleva a universalizar y deslugarizar las antropologías metropolitanas. Pienso que es un gran aporte el de Cardoso de Oliveira la distinción de antropologías metropolitanas-periféricas, me parece acertada esa distinción, pero tomo distancia con la idea que hay una comunalidad de las antropologías fundada en una matriz paradigmática supuestamente derivada de las antropologías metropolitanas universales. En esa idea me parece que todavía hay una cierta aproximación epistemologizante y eurocentrista en cómo entender la diferencia y los procesos de constitución de las antropologías en plural.

Díaz Crovetro: A diferencia con otras disciplinas de las ciencias sociales, la antropología parece tener una mayor dificultad para situarse como un actor político que hace política y que puede ser observado, interna o externamente. Esto contrasta con otras disciplinas, como, por ejemplo, con la sociología del conocimiento, que ha problematizado y sistematizado históricamente dicha cuestión. Pero la antropología al pensarse como tú lo decías, como práctica intelectual, bien podría ser un objeto-sujeto de estudio dentro de lo que sería un paradigma más amplio. ¿Por qué crees tú que la antropología tiene dificultades para situarse en dicho lugar?

Restrepo: A veces esta manera de ver a la antropología como una práctica política cae en la confusión de pensar que política es solamente aquello que tiene que ver con un partido, con el gobierno o con el compromiso con sectores subalternizados. Con Gramsci y Foucault, considero que la noción de política es más compleja, tiene que ver con la manera en cómo vemos el mundo y la manera en que hacemos o dejamos de hacer en el mundo. Entonces la antropología para mí siempre supone lo político porque, querámoslo o no, es un discurso experto que está reforzando o confrontando formas dominantes de ver el mundo y de hacer en el mundo. Por eso la antropología no es algo que simplemente está antes o después de la política, la antropología es política porque interviene en las concepciones del mundo y la antropología puede apoyar, solidificar o desestabilizar o problematizar esas concepciones. Ahora, en la práctica concreta, mucho de lo que se hace en antropología es antropología para el Estado y para el mercado. A pesar de las justificaciones liberales en las que suelen saldar su mala conciencia algunos de estos antropólogos, el grueso de este tipo de práctica es política en el sentido de defensa, solidificación y naturalización del statu quo. De hecho, cada vez menos la antropología es políti- 
ca en el sentido de un pensamiento desestabilizador del statu quo. La política no se puede reducir al campo de la política o a la orientación política que a uno le interesa, pero la antropología como discurso experto es un discurso que constituye el mundo como lo vemos y además se definen una serie de prácticas de dominación o de tecnologías de gobierno. Si lo quieres plantear en otros términos, las articulaciones políticas de la antropología radican en cómo se puede confrontar o cómo se naturalizan determinadas relaciones entre efectos de verdad y tecnologías de poder.

DíAz Crovetto: En tu experiencia como antropólogo que está actuando y que hace investigación en Colombia, ¿te sientes en contraste con otras formas de antropología? ¿Te has sentido excluido de la antropología o de tu condición de antropólogo por no seguir formas canónicas de hacer-pensar antropología?

Restrepo: Digamos que el estilo de hacer antropología que a mí me seduce, es un estilo que subvierte ciertos aspectos de la etiqueta antropológica convencional de ciertas comunidades de antropólogos. En la antropología en Colombia hay una orientación dominante que opera dentro de ciertas etiquetas y protocolos donde mi presencia puede ser molesta o incomoda y genera ciertos ruidos. Es algo que molesta a ciertos sectores privilegiados que conciben la antropología como una práctica fundamentalmente academicista, que está cada vez más colonizada por ciertas maneras de entender lo que debería hacer el antropólogo, que es fundamentalmente escribir papers (así en inglés) para publicar en revistas indexadas y para acrecentar sus grises carreras y cosas como ésas. Desde el comienzo de mi labor como antropólogo, me he encontrado con una suerte de 'ruido' con algunos colegas por cuestiones de origen, de clase social, por estilo o por no seguir la etiqueta, por mi irreverencia. Claro que con otros colegas, ésas han sido razones para que confluyéramos.

También ha habido confrontaciones y críticas con otros sectores por la manera distinta en que concebimos la antropología. Por ejemplo, en Colombia hay un ruido con muchos de quienes asumen que la antropología incluye necesariamente a la arqueología. Desde estudiante, he sido muy crítico de esa visión boasiana de que la antropología como «la ciencia que estudia al hombre compuesta por cuatro ramas: la arqueología, la antropología física o forense o biológica, la antropología sociocultural y la antropología lingüística». Que algunos colegas reciten eso es una idiotez que desconoce la heterogeneidad histórica de la disciplina naturalizando un particular cerramiento arbitrario. Eso 
de que los antropólogos en nuestra formación y en los amarres institucionales hayamos mantenido un forzado maridaje con la arqueología es un resultado de una copia del modelo estadounidense que se ha alimentado de la inercia institucional. Mi abierto cuestionamiento a este sagrado y acrítico sentido común disciplinario de las 'cuatro ramas', en Colombia ha generado mucha inconformidad con no pocos arqueólogos, pero también con antropólogos físicos y forenses. Honestamente pienso que la práctica antropológica en Colombia podría haber sido más incisiva, más cortante si tuviéramos otro tipo de formaciones y de conocimientos en juego en vez de la tiestología (como llamo despectivamente al grueso de la arqueología realmente existente en Colombia que se queda en los tiestos de cerámica). Eso me ha generado muchos problemas con alguna gente en Colombia que asumen como sentido común que la arqueología tiene que estar dentro de la antropología. Yo pienso que no, que debe ser una disciplina aparte, que puede apropiarse de todo lo que le sirva de la antropología, pero que ni la formación antropológica ni la práctica política y profesional del antropólogo requiere necesariamente de la arqueología.

Con respecto a lo que estábamos hablando antes de las antropologías en plural, es importante puntualizar que una cosa es argumentar que la antropología hay que entenderla en su pluralidad, desde las prácticas situadas y realmente existentes, y otra es desconocer que política y éticamente hay que disputar ciertas concepciones de la antropología como prioritarias. Me explico porque esto podría parecer una contradicción. Cuando uno va al mundo y hace un análisis concreto se encuentra que, gústeme o no, han existido múltiples maneras de hacer, de comprender y decir la antropología: por eso hablamos de que hay antropologías en plural. Ahora, cuando pienso cuál es la antropología que considero que vale la pena, entonces me estoy parando ya no en el plano de las prácticas ni en los discursos del ser, sino que me estoy parando en el registro del deber ser, y el registro del deber ser es una disputa política. O sea, la política no está sólo en el plano de las antropologías hacia el mundo, sino que en tanto las antropologías hacen parte del mundo y hacen parte del terreno de la disputa misma. Entonces cuando digo que la antropología no debería tener necesariamente ese maridaje con la arqueología o que la arqueología no debería hacer parte de la formación de los antropólogos lo digo desde una disputa política por el deber ser antropológico.

Otra cosa que me genera mucho ruido en Colombia es la relación con los estudios culturales. Alguna gente piensa que estudios culturales son puro posmodernismo light neoconservador. Muchos lo piensan porque por pura 
pereza intelectual o por cuestiones generacionales dejaron de leer hace años, entonces todo lo que se ha producido desde hace tres o cuatro décadas para acá lo adjetivan de posmodernismo. Por ejemplo, confunden descaradamente posestructuralismo con posmodernidad o posmodernismo, confunden teoría poscolonial con otro tipo de elaboraciones como los estudios de la subalternidad. Así, el hecho que yo esté en un departamento de estudios culturales, que haya propuesto y agenciado ciertas discusiones desde estudios culturales, eso hace que para algunos sea claramente un posmoderno. Ser un posmoderno, para ellos, es una evidente tacha de banalidad teórica, de colonialismo y de sospechosa posición política.

Para otros, los estudios culturales son enemigos de la antropología ya que quieren arrebatarle su campo y objeto. Cierto patriotismo disciplinario habita los corazones de algunos, sobre todo en colegas que suelen tener poco o ningún conocimiento de primera mano de los estudios culturales. No es extraño encontrar en una discusión que no pocos se han quedado con una lectura rápida y acrítica del libro de Carlos Reynoso, ${ }^{5}$ por lo que consideran que los estudios culturales son redundantes y que no ofrecen nada que la antropología no haya hecho antes o que no pueda hacer mejor. Con algunos de estos colegas también tengo a menudo dificultades y encontrones más o menos fuertes.

Díaz Crovetto: ¿Qué relaciones hay entre eso último con tu propuesta de antropologías disidentes? Considerando ese espacio-lugar de enunciación, ¿cuál sería esta propuesta más personal tuya de antropología disidente a diferencia de otras antropologías de las cuales participas, como las antropologías del mundo?

RESTREPO: Lo de antropologías del mundo es una conversación colectiva como tú lo has señalado, que comienza por allá a inicios del $2000^{6}$ y donde hay gente muy valiosa en la definición o en la decantación de cómo conceptualizar antropologías del mundo. A mi manera de ver, el avance conceptual de antropologías del mundo se cristaliza en la noción de antropologías hegemónicas/ antropologías subalternizadas, aunque ahí no todos estamos de acuerdo con los alcances de esta conceptualización. Antropologías del mundo se fundamenta, entre otros, en la discusión geopolítica de antropologías del/en sur de

5. Véase Reynoso (2000).

6. Puede consultarse la página de la Red de Antropologías del mundo, donde se encuentran disponibles los diferentes e-journals: <http:/www.ram-wan.net/>. 
Esteban Krotz y los planteamientos de Cardoso de Oliveira de antropologías metropolitanas-periféricas. Profundizando en el análisis de las relaciones de poder constitutivas entre y en las diferentes antropologías, la conceptualización de antropologías del mundo retoma la noción de hegemonía en el sentido gramsciano para hablar de antropologías hegemónicas y antropologías subalternizadas.

Lo de antropologías disidentes es una cosa que he estado trabajando más yo, como tú lo mencionas, pero es como un camino que no sé dónde me va a llevar, es un camino que hace algunos años, tal vez hace unos 3 a 4 años, empiezo a andar a propósito de mi acercamiento con la teoría queer. ${ }^{7}$ No considero que antropologías disidentes sea algo que se oponga a antropologías del mundo o antropologías del sur o antropologías periféricas-metropolitanas. Es un nivel de análisis distinto, uno sobre las relaciones de poder que constituyen las antropologías que permite o que puede ser visualizado desde la teoría queer. Esta teoría tiene tres elementos que me parecen muy valiosos para entender lo de antropologías disidentes: el primero es que hay que pensar en términos de anormalizaciones, o sea, que existe un dispositivo de poder que es el dispositivo de producir anormalizaciones. Eso se ve en la sexualidad, pero también se da en muchos otros ámbitos de la vida social. La noción de antropologías hegemónicas no atrapa con suficiente detalle esa idea de lo anormal versus lo normal, o mejor de lo desviado versus lo canónico. Ese primer aporte a pensar las antropologías disidentes desde la teoría queer: el poder también pasa por normalizar/anormalizar y que esa normalización/anormalización se naturaliza y se coloca como un lugar no cuestionado, no problemático.

El segundo punto que veo, que es muy sugerente, tiene que ver con la idea de que hay que pensar que el poder opera a partir de categorizaciones, de fijaciones, de visualizaciones. El poder no sólo opera como ocultamiento, como invisibilización, sino que también funciona desde la legibilización, desde la visibilización, desde la categorización. Ése es uno de los mecanismos de ejercicio del poder: la identificación, la visibilidad, la legibilidad. Es el poder que opera en el plano del Estado, pero también es un poder epistémico el de la categorización del mundo. Eso es muy valioso en términos de lo que puede sugerir para pensar que existen un conjunto de prácticas antropológicas que no son entendidas o pensadas desde el canon o desde la normalización, desde

7. Para una introducción a la teoría queer, véase Fonseca y Quintero (2009) y Ortega (2008). 
lo que aparece como antropología, y que se mantienen como no visibles. Toda esa serie de prácticas, discursos, subjetividades que no son atrapables por el aparato de captura de las antropologías normalizadas es precisamente lo que constituiría ese ámbito de las antropologías disidentes.

El tercer elemento importante de la teoría queer para pensar antropologías disidentes consiste en su problematización a las políticas de la identidad y del reconocimiento. Si uno está en la lógica de la política de la identidad se corre el riesgo de la fijación, la sedimentación, la interpelación y la legitimación de dispositivos categoriales y de poder. La teoría queer alerta sobre los riesgos en las políticas de la identidad, y todavía más cuando las políticas de la identidad operan como reconocimiento, como pidiéndole al amo: "por favor, reconózcanos a nosotros en estos términos». Este tercer elemento es un elemento, me parece, muy subversivo, de insolencia, de no querer ser u operar en el plano de la identidad, de la política del reconocimiento. Diría, para cerrar el punto, que el espíritu de la teoría queer es un espíritu de irreverencia que a mí me apasiona, eso de: «somos maricones, iy qué!», o sea, «nos han querido desconocer, patologizar, anormalizar como maricones, pero nos paramos, somos maricones iy qué!». De esta manera se le enrostra al poder el lugar de desviado para perturbarlo, desestabilizarlo, al ponerlo en evidencia. Ese espíritu de irreverencia y de insolencia anarquista de esta teoría queer, es lo que me parece muy valioso como catalizante de prácticas y maneras de hacer antropología que no se detentan en pedir permiso, en solicitar reconocimiento.

Hay muchos otros aspectos de la teoría queer que son inspiradores para potenciar las antropologías disidentes. Por ejemplo, en términos de estilo, la teoría queer escribe en una lógica y en una narrativa distinta, la teoría queer se hace cuerpo. Desde el cuerpo hay toda una inscripción de la teoría, las formas de narrar para qué se hacen. Reconozco que estas elaboraciones están muy en pañales, son ideas, son, digamos, pistas que hay que trabajar con más detalle. Honestamente no sé hacía donde llevará esto. Lo que sí tengo claro es que eso no es una negación de la lectura de antropologías en clave de hegemonía y subalternización. Más bien, es otro nivel para pensar el poder de otra manera.

Díaz CrovetTo: Bueno, Eduardo, muchas gracias por la entrevista. 


\section{Referencias}

Cardoso de Oliveira, Roberto (I988). Sobre o pensamento antropológico. Rio de Janeiro: Tempo Brasileiro.

Fonseca, Carlos y María Luisa Quintero (2009). «La teoría queer: la deconstrucción de las sexualidades periféricas». Sociológica, 24 (69): 43-60.

KROTZ, Esteban (2005). «La producción de la antropología en el sur: Características, perspectivas, interrogantes.» Wan-Ram e-Journal, I: I6I-I70. Disponible en <http://www.ram-wan.net/documents/o5_e_Journal/journal-I/I 2.Krotz.pdf>.

Ortega, Concepción (2008). «Aportaciones del pensamiento queer a una teoría de la transformación social». Cuadernos del Ateneo, 26: 43-56.

Reynoso, Carlos (2000). Apogeo y decadencia de los estudios culturales: Una visión antropológica. México: Gedisa. 
